\title{
Innovative Engineering Applications Developed by Student Group Projects
}

\author{
Mohammad Amin, Laith Al Any, Bhaskar Raj Sinha, Pradip Peter Dey and Muzibul Hayat Khan
}

\begin{abstract}
Developing innovative engineering applications contributes to the prosperity of a nation. To tackle the 21st Century multifaceted issues, engineers need knowledge and experience in diverse areas. This paper describes some of the innovative engineering applications developed at National University in recent years. National University offers an MS in Electrical Engineering where students are encouraged to address real-life issues and provide viable technological solutions through group projects. Each group of 3-4 students was responsible to submit a project proposal. Once approved, the group was responsible to build a prototype for demonstration. At the end, each group made a formal presentation and prototype demonstration in front of a judging panel that comprised of professors and industry professionals. A written project report was submitted and reviewed by the judging panel. Duration of these projects was three months. Most of these projects were well developed and appreciated by the judges and the university administrations.
\end{abstract}

Keywords - Collision, varroosis, wildfire, wireless.

\section{INTRODUCTION}

National University (NU) is an accredited private nonprofit university [1] in California, founded in 1971. Its mission is to provide accessible, achievable higher education to adult learners. In order to fulfill the nation's wireless professional demand and workforce development, NU, in June 2004, launched a new Master of Science program in Wireless Communications (MSWC); the program was nearly unique at that time. The details of this program and its courses are available in the NU 2004 General Catalog [2]. In the course of about sixteen years, the wireless technologies have significantly impacted our personal activities and businesses. In addition to telephone talk and internet services, each day over a trillion dollars traverse the Internet in various forms of electronic payment mechanisms, such as credit cards, debit cards, ATMs, and electronic checks.

When MSWC program was developed in 2004, only $2 \mathrm{G}$ and $3 \mathrm{G}$ wireless technologies were used, but today $5 \mathrm{G}$ technology is in progress. In order to keep the program up to date and meet the multi-faceted challenges in this field, the MSWC program was reviewed in 2015 by a group of experts from the industries and the academia and redeveloped with a new name. The

Manuscript received November 12, 2019. This work was supported in part by the Department of Engineering and Computing, National University.

Mohammad Amin, Bhaskar Raj Sinha, and Pradip Peter Dey are with National University, San Diego, California, USA.

Laith Al Any is with the US Navy, San Diego, California, USA.

Muzibul Hayat Khan is with Kyocera International Inc., Santa Clara, California, USA. program is now known as Master of Science in Electrical Engineering (MSEE) with specialization in Wireless Communications [3]. The NU's MSEE program provides students opportunity to focus their entire degree program through 12 courses devoted to their chosen field of study. Each class at NU is being offered in four weeks where working adult students can focus on one subject area at a time and finish their degrees faster.

In this MSEE program, all students first take 10 classes where they learn theories and concepts. At the end, students are required to take two capstone classes as group or team (3-4 students per group). Each team completes a research project in three months where students learn how to apply theories in design and development of some important and innovative applications in the field of wireless communications. At NU, the adult learners bring different types of work experience and skills, and each team has diverse expertise. The main purposes of these group projects are to train students on how to conduct research, enhance critical thinking, analyze complex problems, develop solutions in multiple ways, build the prototype, and write a research report. Students also get opportunities to gain experience in collaborative team efforts, build working relationships with other team members, understand the leadership and team members' roles, address different critical issues based on individual team member's expertise, and meet the time deadline. There are several overarching academic training goals for the projects: (a) test the academic achievements and engineering competence; (b) promote the importance of teamwork in addressing time constraint in real life engineering projects; (c) develop skills to apply engineering knowledge and expertise in solving a real-life issue; (d) develop important project management skills to manage task execution; and (e) boost "can do" attitudes among students. This paper briefly reports on some innovative engineering applications developed through the team project efforts.

\section{INNOVATIVE ENGINEERING APPLICATIONS}

Students are always encouraged to develop innovative project ideas independently. They are allowed to consult faculty members for guidance. Students usually brainstorm with their own ideas, perform a literature survey, and then discuss their ideas with engineering faculty members before selecting a promising project topic. Following are some brief descriptions of exemplary innovative applications developed by student groups at National University. The details of each project can be found in the following references [4]-[14]. 


\section{A. An Innovative Method to Fight Varroosis [4]}

After conducting a thorough literature review and market survey, a new device was proposed and designed using two wireless sensors to detect and eliminate Varroa mites in a beehive. This proposed device is portable, has internet connectivity via a SIM7000A LTE shield, and can be operated from a $\mathrm{PC}$ or mobile phone from a remote location. A prototype has been developed and tested for proof of concept. This new user-friendly device is called the "BMitesFlee". The primary objective of this study was to design and develop an affordable, adaptable, real-time wireless device that can be deployed in the field without disrupting any other devices used in the beehive farm. It is capable of destroying and eliminating all the Varroa mites in the beehive using an ultrasonic frequency. It is expected to provide beekeepers a way to automate their beekeeping system without worrying about those pesky Varroa mites which are harmful for the honey industry.

\section{B. DSRC Module for Collision Avoidance [5]}

Since 1996, every vehicle manufactured in the United States has been equipped with an On-Board Diagnostic (OBD) computer to monitor its functions. The objective of this project was to design a cost-effective module that can be connected to a vehicle's OBD port and communicate with other vehicles' modules to inform a driver of their surroundings with regards to other vehicles, in order to reduce accidents, more specifically, rear-end collisions. A pair of modules that are being designed in this project will include a Raspberry $\mathrm{Pi} 3$ connected to a touchscreen (to act as a module) and an OBDII adapter (in order to draw data from the vehicle). One of the purposes of this project was to show that the efforts of pushing vehicular communication as a standard for smarter transportation in the future is worth pursuing. A prototype was developed and tested for proof of concept.

\section{Eye-Cane [6]}

Eye-cane is a cost-effective solution for visually impaired people. There is a need for reliable and economic system that would assist visually challenged people to lead a less intrusive life. Advancements in the fields of embedded systems and wireless technology opened the path to wide range of opportunities for research and development in this technical space. Technologies that are addressing the issues in question are available in the market, but these are expensive, bulky and intrusive. In this project, a relatively inexpensive system was proposed which is user friendly, functional, accurate and reliable. This device is called "Eye-Cane" and it aims to detect the surrounding areas and assist safe walking for visually challenged people. A prototype was developed and tested for successful results. Inexpensive products can be developed based the research carried out in this project.

\section{IoT Applications for Agriculture Control System [7]}

This project introduced a new IOT system that was developed using hardware and software to monitor different elements in a farm's soil. This proposed system collected data and provided the necessary treatments from a remote site using wireless technology. This system can be setup for a specific crop which needs certain soil conditions. The goal of this project was to solve one of the main issues that farmers have been facing due to climate change e.g. dramatic changes in the salinity and $\mathrm{pH}$ levels of soil. In the last two decades, the California Central Valley has lost millions of dollars due to the increase of salinity and $\mathrm{pH}$ levels in the soil. This new IOT device is capable of detecting temperature, moisture, humidity, salinity, and $\mathrm{pH}$ levels of any agricultural land. It can be run automatically to measure these data and provide the necessary treatment as needed. This system is simple and can be operated from a remote location by using user-friendly interfaces (web based and mobile app). A prototype was developed and tested for proof of concept.

\section{E. The Smart Flying Mailbox (SFM) [8]}

This project proposed a technical solution to change the traditional mailboxes for residential and commercial uses. The SFM is a device designed and built using a cutting-edge technology which brings life to any mailbox anywhere around the world. The SFM can fly, deliver the mail with a click of a button through a unique smart mobile application. The SFM is designed with a custom built-in Drone, GPS Tracking, Precision Landing technology, Smart Camera and mobile application. The SFM was designed to notify the user through a mobile device of a mail arrival, ability to find its exact landing and base location automatically, provide the user with a live video streaming, and allows the user to take photos through the mobile application. This device provides coverage for a 5 miles radius space. The SFM can be self-installed, equipped with a uniquely designed and engineered landing base, referred to as the "Smart Landing Base", and an Android based mobile application that is compatible with Android v7 or higher.

\section{F. Camp Safety System [9]}

There is an urgent need for a reliable, low cost, safety alert system to protect people who live in tents in refugee camps. The goal of this project was to design a wireless safety alarm system to protect and reduce the number of accidents that may occur in these camps, leading to serious injury or death of the residents inside the tents from gas leak, fire burn, heatstroke or freezing temperature. This system was based on the IoT concepts. It's a network of connected objects able to collect and exchange data using embedded devices like sensors (gas, heat and flame sensors) and the Arduino microcontroller. This developed product is a stand-alone connected system that can be monitored and/or controlled from remote locations. Development included a monitoring system for gas leak detection, fire/flame detection and temperature detection through a wireless monitoring system. The gas sensor used in this study was MQ9, TMP36 temperature sensor and a Gikfun flame sensor. The Arduino Uno R3 microcontroller board was used for the project in order to monitor the alarm system. Additionally, $\mathrm{C}++$ programming language was used as the micro-controller code. A Software Application was designed and implemented using $\mathrm{C \#}$ for the monitoring room computer screen. Also, an IOS/Android 
application was designed to receive notifications from the sensors using BLYNK open source. The system consists of a microcontroller, 3 sensors LEDs, a buzzer, an RF $433 \mathrm{MHz}$ transmitter, receiver link module, monitoring room computer, and an IOS or Android phone.

\section{G. Smart Gas Leakage Monitoring System [10]}

All flammable gases such as liquefied petroleum and cooking gas are potential health hazards and dangerous for the environment because these hazards may cause fires, explosions and air pollutions. A gas monitoring system is essential in order to reduce these hazards. In this project, a smart gas monitoring system was designed and developed using sensors, RFID, hardware, software, and wireless network sensor technologies. A prototype was built using two gas sensors installed at two different locations. The proposed system is capable of detecting gas leakage and identifying the affected locations, sounding alarms, closing the main gas valve and sending a message to the respective parties including 911, fire stations, landlords, neighbors, gas companies, etc. This system has potential to use for both residential and commercial areas.

\section{H. Water Quality Measurement System [11]}

Sixty-seven percent of the earth surface is covered by water and $75 \%$ of the human body contains water. There is no doubt that water is one of the most essential ingredients of life. The need for effective and efficient water quality measurement is critical. The traditional methods of water quality measurement rely on sample collection, testing and data analysis in remote laboratories. These methods are expensive and incapable of performing real-time data analysis and producing useful information. These are not suitable for fast information dissemination to the relevant stakeholders for making timely decisions. In this project, a new innovative idea was used to develop a smart measurement system capable of dealing with real-time sample collection, and data analysis that would generate accurate information and quickly disseminate that information through wireless technologies. A prototype was developed using software, hardware and wireless sensor network (WSN) technologies. Three different sensors were used in the prototype to measure the following qualities of water: $\mathrm{pH}$, turbidity and water levels. This new system can potentially add more sensors including temperature, conductivity, viscosity, density, pressure, color, etc. These preliminary results indicate that the new proposed system has great potentials for real world applications. This new proposed system will help to monitor water quality from a remote location, and it will save time, sample collection efforts and money.

\section{Tracking of Ground Operations Vehicles on Airfields and} Airports [12]

The project helps ground operations vehicles (GOVs) in the airports to avoid runway and taxiway incursions by developing an android app and installing it on a smart device mounted on the dashboard of the GOVs. This app is designed to track the GOV while it is moving in the airfield or airport area and to warn the driver of the GOV as well as the air traffic control tower (ATCT) whenever the GOV reaches a point of possible incursions.

\section{J. Wildfire Detection and Monitoring System [13]}

The main objective of this project was to design a monitoring system that would be able to detect wildfires as they occur and alert people immediately. Wildfire is a serious phenomenon affecting many regions in the country, especially California. Every year, these wildfires destroy thousands of acres of land, vegetation, livestock and human lives. Many fire detection techniques are available, but most of these are not capable of detecting fire remotely through wireless. "Wildfire Detection and Monitoring System" is a new system that will help the firefighters to have a better understanding of the cause and intensity of the wildfire, thus making it easy for them to implement better extinguishing plans. In this new design, the forest's geographical region was viewed as a grid of several small zones by the control command. Detection equipment, called fire sensors, were deployed at several locations in each zone. All the fire sensors of a zone were linked to a control unit through an RF channel. The control unit, in turn, was linked to the control command through a GSM network. The control command had the information about ambient temperature, smoke, ash, humidity, and pressure of each zone and its exact location. In case of fire, the sensors sent an alert message to the control unit which in turn informed the control command. This alert message was finally passed on to the firefighter's mobile phone. This procedure allowed the firefighters to make proper extinguishing plans and take the necessary actions immediately. In this project, a prototype was developed and tested with two sensors deployed at two different locations. The system was able to detect fires, identify locations and sent SMS to mobile phones. This Wildfire Detection and Monitoring System will help to extinguish fire quickly, reduce property damage, save lives, and protect forest resources.

\section{K. Smart Phone Book Search [14]}

Mobile communication is one of the most significant developments in technology over the past two decades. Mobile phones have invaded our daily lives by creating a new lifestyle and transforming the existing information using communication system in our society. Rapid advances in this field have transformed the mobile phone from a device of voice communication into a powerful device that supports a wide variety of services like email, navigation, online shopping and entertainment. It has also opened the doors to an endless possibility of new applications to provide more services. The cutting-edge mobile phone supports various features like sending an SMS from one phone to the other, listening to music, playing games, watching videos and many more. In today's world, most of us are inextricably dependent on our mobile phones. They contain important information that we need frequently. Further, the contact information available on our handsets has become one of the main sources of communication. So, it would be unthinkable if we misplaced the device and had no way to retrieve the data stored on the mobile 
phone. This is one of the key motivations behind this project. The primary aim of the project was to address a scenario when a user forgets to carry his mobile phone and is instantly in need of certain contact information to make a few prompt calls. A solution to this scenario was to develop a new application that will help the user to access the phone book and retrieve the contact information remotely by sending an SMS. This newly developed application is called the 'Smart Phone Book Search', which helps the user to access the mobile phone remotely via SMS. In this project, the project group members used a Symbian Operating System Version 7.0 compatible Nokia 6600 mobile phone. The 'Smart Phone Book Search' application was designed to search the contact database in the mobile phone to retrieve the information related to a query contact. It retrieved the contact information such as the first name, last name and the mobile phone number from the user's phone book in a specified format. This newly developed application was built and tested to retrieve single and multiple contact lists from the user's phone book. The project report included commands and snapshots for different scenarios from the project.

\section{DISCUSSION}

In the first month of the project class, each team meets their instructor twice a week, conducts a thorough research and submits a viable (feasible) project proposal for review and approval. In the initial proposal phase, students discuss various project ideas among themselves and with engineering faculty members and some industry representatives in order to explore best ideas for innovative projects. When the project proposals are reviewed, and approved student teams start working on the next phases. That is, upon receiving the approval, students meet once a week in second and third months and each team builds a prototype for demonstration, writes a formal project report for review and makes a presentation in-front of a faculty judging panel comprised of both university professors and industry professionals. This panel judges each project using rubrics developed by the Academic Program Director and assigns scores for both presentation and report. All the projects mentioned in this paper were well developed and received laudatory comments from the judges. The panel members made excellent comments on students' innovative problem-solving skills. The roles of innovation in modern industry, academia and society are becoming increasingly important [15]-[19]. The new wave of technological innovations is changing the way we live and learn. "Arguably, everyone stands to gain from global innovation. More resources are now spent on innovation and related factors globally than at any other given point in human history" [18]. Innovative project ideas generally create an immersive learning environment where students can experiment with many alternative solutions. Student teams are able to solve complex real world problems by considering wide range of alternatives and their relative advantages and disadvantages.

\section{CONCLUding REMARKS}

Innovation means doing things in new ways. Most of the time innovative ideas and processes generate from a group of diverse participants. In engineering, innovation generally means changing the conventional design and production processes to produce effective and better products [15-18]. Majority of the students enrolled in the MSEE program at NU have work experience and are looking for education and training to help them advance their career. So, the program emphasizes on various theoretical and practical aspects of Computer and Electrical Engineering knowledge and skills. All the group projects were completed by these diverse participants and they introduced new ways of doing things for better and efficient engineering products. The authors of this paper have expertise in diverse areas including electrical engineering, wireless communications, materials engineering, computer engineering, software engineering, and business. They were directly involved with these projects and supervised them closely in order to make sure students are learning by doing. These projects were evaluated and judged as innovative and successful.

\section{ACKNOWLEDGMENT}

Authors are grateful to National University Faculty, Administration and Staff for their continued support and valuable services.

\section{REFERENCES}

[1] National University, 11255 North Torrey Pines Road, La Jolla, CA, U.S.A. https://www.nu.edu

[2] MSWC Program, NU General Catalog, Volume 67 September 1, 2003. https://assets.nu.edu/assets/resources/pageResources/Catalog67.pdf

[3] MSEE Program, NU General Catalog, Volume 79 | August 31, 2015 https://www.nu.edu/wp-content/uploads/2018/11/NU15_2951_General_ Catalog_79_Web.pdf.

[4] A. Bilyy, I. Tkachenko and M. L. Montique. (October 2018). An Innovative Method to Fight Varroosis. Department of Engineering and Computing, National University, San Diego, California, USA http://asethome.org/innovativeprojects/Hive_Report.pdf.

[5] S. Edquiban, R. Burdett and J. T. Fellows. (October 2018). DSRC Module for Collision Avoidance. Department of Engineering and Computing, National University, San Diego, California, USA http://asethome.org/innovativeprojects/_Dsrc_Capstone_Report.pdf.

[6] N. Kallakuri, M. Saad, A. Astikar and D. Haile. (October 2018). Eye-Cane Department of Engineering and Computing, National University, San Diego, California, USA http://asethome.org/innovativeprojects/Eye_Cane_Report.pdf.

[7] A. K. Alhadithi, B. Amir, W. Zawaideh and G. Feliciano. (October 2018). IoT Applications for Agriculture Control System. Department of Engineering and Computing, National University, San Diego, California, USA http://asethome.org/innovativeprojects/IoT_Application.pdf.

[8] A. Noori, R. Alexanian and R. Jawhar. (October 2017). The Smart Flying Mailbox. Department of Engineering and Computing, National University, San Diego, California, USA http://asethome.org/innovativeprojects/Flying-Mailbox.pdf.

[9] O. Al Obaidi, A. Alwan, M. Almahdawi and B. Ibrahim. (October 2017). Camp Safety System. Department of Engineering and Computing, National University, San Diego, California, USA http://asethome.org/innovativeprojects/Camp_Safety_System.pdf

[10] A. B. Salman, H. Kala and A. Ali. (October 2016), Smart Gas Leakage Monitoring System. Department of Engineering and Computing, National University, San Diego, California, USA. http://asethome.org/innovativeprojects/Gas_Detection_System.pdf

[11] F. Al Dabbagh, H. Abdulwahhab, A. Al Dulaimi, and E. Al Ameri. (October 2016). Water Quality Measurement System. Department of Engineering and Computing, National University, San Diego, California, http://asethome.org/innovativeprojects/Water_Quailty_Monitoring_syst em.pdf

[12] Y. Shaheen, M. Maroof, H. Al Jubouri, and J. Pintaso (October 2016). Tracking of Ground Operations Vehicles on Airfields and Airports. 
Department of Engineering and Computing, National University, San Diego,California.

http://asethome.org/innovativeprojects/Ground_Operational.pdf

[13] V. Dharanalakota, S. Komma, F. Maradona and V. Gona (2009). Wildfire Detection and Monitoring System. Department of engineering and Computing, National University, San Diego, California, U.S.A. http://asethome.org/innovativeprojects/

[14] C. Prakash, M. Maladkar and S. Narkhade, (2009). Smart Phone Book Search. Department of Engineering and Computing, National University, San Diego, California, USA http://asethome.org/innovativeprojects/

[15] J. Fagerberg, D. Mowery, and R. Nelson. (2004). The Oxford Handbook of Innovation, Oxford, Oxford University Press, 2004.

[16] Business: Australian Government (November 2018). https://www.business.gov.au/change-and-growth/innovation

[17] S. G. Bilén and R. F. Devon (August 2005). Innovative Engineering Design Education. International Conference on Engineering Design Iced $05 \quad$ Melbourne, August 15-18, 2005. https://www.designsociety.org/publication/23087/INNOVATIVE+ENGI NEERING+DESIGN+EDUCATION

[18] S. Dutta, B. Lanvin, and Wunch-Vincent (2016). The Global Innovation Index 2016: Winning with Global Innovation. Retrieved, July 2019 from: https://www.globalinnovationindex.org/userfiles/file/reportpdf/gii-full-re port-2016-v1.pdf

[19] C. Cavalcante Koike, D. Viana, and F. Vidal "Mechanical engineering, computer science and art in interdisciplinary project-based learning projects," International Journal of Mechanical Engineering Education, vol. 46, no. 1, pp 83-94, January 2018. https://doi.org/10.1177/0306419017715427

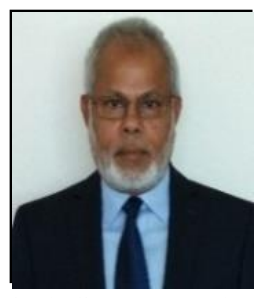

Dr. Mohammad Amin received his Ph.D. and MS degrees in Electrical Engineering \& Computer Engineering, and MS degree in Solid State Physics from Marquette University, Milwaukee, Wisconsin. $\mathrm{He}$ also received M.Sc. and B.Sc. degrees in Physics from University of Dhaka, Bangladesh. Currently, he is working as a Professor of Engineering at National University, San Diego, California. Before joining $\mathrm{NU}$, he worked for many organizations including General Electric, New Jersey Electric Power, Marquette University, University of Notre Dame, College of Technology-Makkah, Waukesha County Technical College, University of Wisconsin Center-Sheboygan, etc. He has published and presented more than 100 articles and papers, 3 US patents, and edited 9 books/proceedings. His current research of interests are applications of wireless sensors, computer applications, and quantum computing. As of today, he organized the International Conference on Computer Science and its Applications (ICCSA2002-2006) as Program Co-Chair, the International Computer Science and Technology Conference (ICSTC-2008) as Database Track Chair, and the American Society for Engineering Education/Pacific South West Conference (ASEE/PSW-2009 \& 2015) as Program Chair. mamin@nu.edu

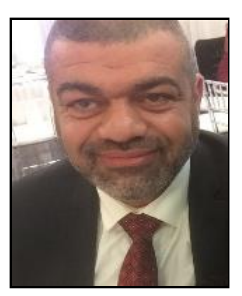

Mr. Laith Al Any received his M.Sc. in Communication Systems Engineering from University of Technology, Baghdad, Iraq in 1998. He is a registered Professional Engineer $(\mathrm{PE})$ in Electrical Engineering in California and Arizona states, USA since 2014. Currently, he is a DM Electrical Engineer at NAVFAC SW, US Navy, San Diego, California. He is also an Associate Faculty at National University, San Diego, California. His professional experience includes working as a Technical Manager for Lucent Technology, Bell lab Innovation, and Motorola, in telecom projects in the Middle East. He also worked as an Instructor for Grossmont Community College, California, and created and ran the FE/EIT Board for Professional Engineers and Surveyors. His experience includes working as an instructor for Baghdad University, Technology University in Iraq, and University of Sharjah, UAE.

Email: Laith.alany@navy.mil and lalany@nu.edu.

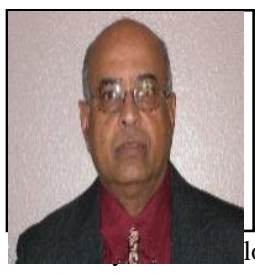

Dr. Bhaskar Raj Sinha is a Professor in the Department of Engineering and Computing, National University, San Diego, California. He earned his $\mathrm{Ph} . \mathrm{D}$. in Electrical Engineering from University of California, Davis, California, M.B.A from California State University, Hayward, California, M.Sc. in Electrical Engineering from o, Ontario, Canada, and his B.Tech. in Electrical Engineering from the Indian Institute of Technology (IIT), Kanpur, India. He has over forty years of experience working in the industry and academia. His industry experience includes working for established high tech companies like IBM, Oracle, and Bell Northern Research, and start-up company One Touch Systems. His experience in academia includes working with the Higher Colleges of Technology in the United Arab Emirates, and, since 2009, with National University in the Department of Engineering and Computing in San Diego, California. Dr. Sinha has over seventy publications in national and international journals and conference proceedings. His research interests are in the areas of computer architecture, digital systems, computer science, and management information systems. bsinha@nu.edu

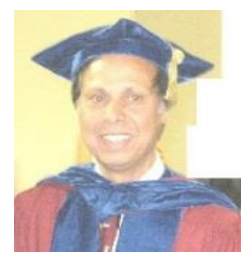

Dr. Pradip Peter Dey is a Professor in the Department of Engineering and Computing, National University, 3678 Aero Court Drive, San Diego, California 92123, USA. He received his Ph.D. from University of Pennsylvania, Philadelphia, USA. He primarily teaches in the MS in Computer Science program. He received the Best Teaching Award in 2014. His research interests are computational models, innovative software design, mathematical reasoning, visualizations, User Interfaces and Computer Science education. , He organized five times the International Conference on Computer Science and its Applications (ICCSA2002-2006) as Program Co-Chair, and two times the American Society for Engineering Education/Pacific South West Conference (ASEE/PSW-2009 \& 2015) as Program Co-Chair Email: pdey@ nu.edu.

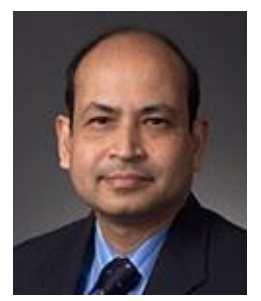

Dr. Muzibul Hayat Khan received his B.S. and M.S. degrees from St. Petersburg State University and Ph.D. degree from Concordia University. He joined Kyocera International Inc. (KCI) in 2013 and has held many lead responsibilities in the areas of $R \& D$ Strategy, Strategic Planning and Product Planning. $\mathrm{He}$ is responsible for Corporate and Technology Planning functions, charting the evolution of the business plan and technology portfolio for $\mathrm{KCI}$ Before joining Kyocera, Dr. Khan served in senior leadership roles in the global telecommunications industry, including Chief Technology Officer (CTO) for Huawei Devices USA, Vice President \& Head of Research \& Development for Nokia CDMA terminals, and Vice President of Product Management \& Engineering for the wireless terminals division of Samsung Telecommunications America. He began his career as an associate professor of electrical engineering at Lakehead University, Canada. He has authored more than 30 technical publications and received five patents with several patents pending. Email: Muzib100@gmail.com. 